\title{
DESEMPENHO E CARACTERÍSTICAS DO SÊMEN DE GALOS LEVES SUBMETIDOS A DIFERENTES FOTOPERÍODOS ${ }^{1}$
}

\author{
Performance and semen characteristics of light roosters submitted to different photoperiods
}

\author{
Mônica Patrícia Maciel², Judas Tadeu de Barros Cotta ${ }^{3}$, Luis David Solis Murgas ${ }^{4}$, \\ Rilke Tadeu Fonseca de Freitas ${ }^{5}$
}

\begin{abstract}
RESUMO
Com o objetivo de avaliar os efeitos de diferentes fotoperíodos sobre o desempenho e características do sêmen de galos de linhagem leve, foi conduzido um experimento no Departamento de Zootecnia da Universidade Federal de Lavras. Foram utilizados 24 galos da linhagem Lohman LSL com idade inicial de 19 semanas, sendo os mesmos submetidos a 3 tratamentos: 1) fotoperíodo contínuo; 2) fotoperíodo intermitente e 3 ) fotoperíodo natural crescente. As aves foram alojadas em galpão dividido em 3 ambientes, de forma que a iluminação de um, não interferisse na do outro. O delineamento experimental foi inteiramente casualizado, com 8 repetições, sendo a unidade experimental constituída de 1 galo. O período experimental teve duração de 20 semanas e as variáveis avaliadas foram: consumo de ração (g/ave/dia); peso corporal (g); produção de sêmen (ml), motilidade (\%) e vigor espermáticos $(0 \mathrm{a}$ 5), concentração espermática (número de células x $10^{9}$ ), número de células de sêmen totais (NCT- volume x concentração) e morfologia espermática (alterações de cabeça, cauda e alterações totais). Os galos submetidos ao fotoperíodo contínuo apresentaram maior consumo de ração $(\mathrm{P}<0,05)$, não havendo influência significativa $(\mathrm{P}>0,05)$ dos fotoperíodos sobre as demais variáveis. Concluiu-se que os fotoperíodos contínuo, intermitente ou natural crescente podem ser utilizados em galpões abertos para galos leves durante o período reprodutivo, sem prejuízo às características do sêmen.
\end{abstract}

Termos para indexação: Luz intermitente, luz natural, reprodução, sêmen.

\begin{abstract}
With the aim of evaluating the effects of different photoperiods on the performance and semen characteristics in roosters of light strains, an experiment was carried out at Animal Science Department of the Universidade Federal de Lavras. A total of 24 roosters of the Lohman LSL strain (light), aged 19 weeks was used, they themselves being submitted to 3 treatments: 1) continuous photoperiod; 2) intermittent photoperiod and 3) growing natural photoperiod. The birds were housed in a shelter divided into 3 environments, so that the lighting of one did not interfere upon the other. The experimental design was completely randomized, with 8 replicates. The experimental unit being made up of 1 rooster. The experimental period lasted 20 weeks and the variables evaluated were: feed intake (g/bird/day), body weight (g), seminal volume (ml), spermatic motility (\%) and vigor (0 to 5), spermatic concentration (number of cells $\mathrm{x} 10^{9}$ ), number of total spermatic cells (NCT- volume x concentration) and spermatic morphology (alterations of head, tail and total alterations). The roosters submitted to continuous light showed increased feed intake $(\mathrm{P}<0,05)$, but didn't influence $(\mathrm{P}>0.05)$ of the photoperiods on the other variables. One concluded that the continuous photoperiods, intermittent or growing natural light may be utilized in open shelters for light roosters over the reproductive period without harming the semen characteristics.
\end{abstract}

Index terms: Intermittent light, natural ligh, reproduction, semen.

\section{(Recebido em 9 de março de 2006 e aprovado em 30 de outubro de 2006)}

\section{INTRODUÇÃo}

Um dos fatores ambientais que afetam a reprodução dos galos é o fotoperíodo. Em aves de postura já é bastante conhecida a função da luz artificial com o objetivo de aumentar o fotoperíodo e estimular a produção de ovos.
Entretanto, informações sobre os efeitos da luz sobre as funções reprodutivas do macho são limitadas.

Um dos programas de luz utilizados atualmente em países da Europa e Estados Unidos é o chamado "programa de iluminação intermitente", que fornece combinações alternadas de luz e escuro. Ele prevê uma iluminação

\footnotetext{
'Parte da tese apresentada à Universidade Federal de Lavras (UFLA), pelo primeiro autor, para a obtenção do título de Doutor em Zootecnia na área de concentração em Produção Animal;

2Zootecnista, Doutora em Produção Animal - Departamento de Ciências Agrárias/DCA - Universidade Estadual de Montes Claros/UNIMONTES - Rua Reinaldo Viana, 2630 - Bico da Pedra - 39440-000 - Janaúba, MG - mpmaciel@hotmail.com

${ }^{3}$ Médico Veterinário, Doutor, Professor Adjunto - Departamento de Zootecnia/DZO - Universidade Federal de Lavras/UFLA - Cx. P. 3037 - $37200-000$ Lavras, MG - jtbcotta@ufla.br

${ }^{4}$ Médico Veterinário, Doutor, Professor Adjunto - Departamento de Medicina Veterinária/DMV - Universidade Federal de Lavras/UFLA - Cx. P. 3037 37200-000 - Lavras, MG - Ismurgas@ufla.br

5Zootecnista, Doutor, Professor Titular - Departamento de Zootecnia/DZO - Universidade Federal de Lavras/UFLA - Cx. P. 3037 - $37200-000$ - Lavras, MG - rilke@ufla.br
} 
fracionada descontínua e baseia-se no conceito de "dia subjetivo", que denomina o período durante o qual o animal permanece fisiologicamente ativo, mesmo na escuridão. A adoção deste conceito de manejo permite uma redução na utilização de iluminação artificial na produção de aves, sendo uma boa maneira de economizar eletricidade. No Brasil, poucos pesquisadores têm dado a devida atenção a este tema. Muitos produtores julgam que quanto mais luz fornecida às aves melhor será o desempenho das mesmas (COTTA, 2002).

Existem poucos trabalhos na literatura referentes aos efeitos do fotoperíodo intermitente sobre as características reprodutivas dos machos. Siopes (1983) estudou a influência de luz intermitente sobre as características seminais de perus adultos. Observou-se que, embora os perus tivessem mantido pesos corporais semelhantes, aqueles que receberam luz intermitente consumiram menos ração e produziram quantidades equivalentes de sêmen com número de espermatozóides semelhantes durante todo o período experimental em comparação ao tratamento controle (luz contínua). Foi observada uma menor incidência de espermatozóides morfologicamente anormais nos animais submetidos à luz intermitente, havendo uma economia de $73 \%$ de energia elétrica com a utilização dos fotoperíodos intermitentes.

Em trabalho com perus sexualmente maduros, Bacon et al. (1994), submeteram os mesmos a fotoperíodos intermitentes e contínuos. Não foram observadas diferenças entre os tratamentos com relação ao peso corporal, produção de sêmen e secreção de LH e testosterona.

Sauveur (1998) afirma que o galo apresenta uma fase de fotossensibilidade máxima ao longo de 24 horas e responde conforme a noção de "dia subjetivo". Uma duração de 8 horas de luz por dia, dividida em dois períodos de 4 horas espaçados de 6 a 8 horas (repartição da iluminação ou dia subjetivo), é tão eficiente para a produção de sêmen e o crescimento testicular quanto os fotoperíodos contínuos (14 horas).

Freitas et al. (2005) submeteram poedeiras leves em final de postura a três tipos de regimes luminosos: contínuo (natural + artificial), natural crescente e intermitente (natural +15 segundos de luz). Foi observado um menor consumo de ração pelas aves sob fotoperíodo intermitente e natural. Os autores observaram que as poedeiras leves podem ser criadas com iluminação intermitente, sem diminuir a sua produtividade e sem alterar as características dos ovos.

Conduziu-se este trabalho, com o objetivo de avaliar os efeitos de diferentes programas de luz sobre o desempenho e características do sêmen em galos de linhagem leve.

\section{MATERIAL E MÉTODOS}

O experimento foi conduzido no Setor de Avicultura do Departamento de Zootecnia e no Laboratório de Fisiologia Animal do Departamento de Medicina Veterinária da Universidade Federal de Lavras (UFLA). O período experimental teve a duração de 20 semanas, estendendose de julho a dezembro de 2004. Foi utilizado um galpão dividido em 3 compartimentos por lona de plástico preta, de forma a evitar a passagem de luz de um ambiente para outro. Foram utilizados 24 galos da linhagem Lohmann LSL com idade inicial de 19 semanas (8 por tratamento), sendo os mesmos alojados individualmente em cada gaiola. A ração fornecida durante o período experimental, à base de milho e farelo de soja, continha $14,8 \%$ de proteína bruta, $2900 \mathrm{kcal}$ de energia metabolizável, $1 \%$ de cálcio e $0,37 \%$ de fósforo disponível. Em dois dos ambientes experimentais foram instalados "timers" com o objetivo de acender e apagar as luzes nos horários determinados. No ambiente com iluminação intermitente, acoplado ao "timer", foi instalado um temporizador que possibilitou desligar as luzes 15 segundos após serem acesas. As lâmpadas utilizadas foram do tipo incandescente de 60 Watts, sendo fornecida uma intensidade mínima de luz de 12,6 Lux.

A partir da idade de 19 semanas, foi feita a estimulação diária dos galos para as coletas de sêmen para que os mesmos fossem condicionados ao procedimento na fase experimental. A estimulação foi realizada pelo método de massagem abdominal, conforme Burrows \& Quinn (1937).

Os tratamentos utilizados foram: 1) fotoperíodo contínuo: as lâmpadas foram acesas às 4 horas e desligadas na aurora, acesas novamente ao anoitecer e apagadas às 19 horas, de forma a receberem um fotoperíodo contínuo de 15 horas; 2) fotoperíodo intermitente: as lâmpadas foram acesas às 4 horas e apagadas 15 segundos após. Eram novamente acesas às 18 horas, 59 minutos e 45 segundos e apagadas às 19 horas. Evocando-se o conceito de "dia subjetivo", foi fornecido, então, um fotoperíodo intermitente de 15 horas; 3 ) fotoperíodo natural: somente foi fornecida iluminação natural crescente.

As avaliações de desempenho e características seminais foram feitas nas idades de 24, 29, 34 e 39 semanas dos animais. O consumo de ração foi expresso em gramas/ ave/dia e o peso corporal em gramas. Os parâmetros avaliados no sêmen dos galos foram: produção (volume), concentração, número total de células (NCT), motilidade e vigor e morfologia espermática (anormalidades dos espermatozóides). A motilidade geral foi avaliada segundo escala de 0 a 100 . Retirou-se uma gota de sêmen de cada galo imediatamente após a coleta colocando-a sobre lâmina 
recoberta por lamínula previamente aquecida à temperatura de $40^{\circ} \mathrm{C}$ para a leitura no microscópio ótico (40X). O volume de sêmen de cada galo foi medido diretamente na seringa de $0,1 \mathrm{ml}$. Para análise da concentração, foi retirada uma amostra de 10 1/4l de sêmen de cada galo para ser adicionado a $1 \mathrm{ml}$ de solução de formol citrato, sendo a contagem realizada com o uso da Câmara de Newbauer com o resultado expresso em número de células por $\mathrm{ml}$ de sêmen. O NCT foi calculado pela multiplicação da concentração e volume do ejaculado de cada galo. Para avaliação das anormalidades dos espermatozóides, 1 1/41 de sêmen de cada galo foi adicionado a 250 1/41 de solução de formol citrato. Seguidamente, no microscópio de contraste de fase com aumento de $1000 \mathrm{X}$, realizou-se a contagem de 100 células, expressando as alterações morfológicas em percentagem. As alterações dos espermatozóides avaliadas foram alterações de cabeça, cauda e alterações totais. Houve transformação de dados para ajustar a normalidade para as seguintes variáveis: motilidade espermática (arcoseno de X/100); alterações de cabeça dos espermatozóides (raiz de $\mathrm{X}+0,5$ ); alterações de cauda dos espermatozóides e alterações totais (raiz de X). As diferenças entre tratamentos foram comparadas pelo teste Scott-Knott (5\%) e para análise dos dados foi utilizado o pacote computacional SISVAR, descrito por Ferreira (2000).

\section{RESULTADOS E DISCUSSÃO}

Na Tabela 1 são apresentados os resultados de desempenho e características do sêmen dos galos leves de acordo com o fotoperíodo.

$\mathrm{O}$ consumo de ração foi influenciado $(\mathrm{P}<0,05)$ pelos fotoperíodos. Os galos submetidos aos fotoperíodos intermitente e natural apresentaram menor consumo de ração em comparação com aqueles do fotoperíodo contínuo.

Semelhante ao observado neste experimento, Siopes (1983), estudando a influência de luz intermitente sobre o desempenho e características seminais de perus adultos, observou que os animais que receberam luz intermitente consumiram menos ração que aqueles submetidos ao fotoperíodo contínuo. A explicação para este comportamento não foi conclusiva, mas segundo o autor, houve uma redução da atividade dos animais do fotoperíodo intermitente, gerando uma menor exigência de energia de mantença, levando a um menor consumo de ração.

Em pesquisa recente, Freitas et al. (2005) observaram resultado semelhante quando submeteram poedeiras leves a diferentes fotoperíodos. As aves que receberam iluminação intermitente e natural consumiram menor quantidade de ração, quando comparadas com aquelas que receberam fotoperíodo constante. Porém, Lewis \& Perry (1990) e Morris \& Butler (1995) não encontraram o mesmo resultado com poedeiras e concluíram que o consumo não varia quando são utilizados alguns fotoperíodos intermitentes.

O peso corporal dos galos não foi influenciado (P>0,05) pelos fotoperíodos. Bacon et al. (1994) e Siopes (1983) também não observaram diferenças entre os pesos corporais de perus adultos submetidos aos fotoperíodos contínuo e intermitente, apesar dos animais submetidos a este último terem consumido menor quantidade de ração.

Os resultados de produção de sêmen mostram que não foram observadas diferenças entre os fotoperíodos testados $(\mathrm{P}>0,05)$.

Pesquisas realizadas com linhagens modernas de poedeiras leves (CHARLES \& TUCKER, 1993) afirmam que estas aves são tão geneticamente predispostas à alta produção que praticamente se apresentam refratárias à mudanças de regime luminoso. Isso pode ter acontecido com os galos deste experimento, já que a produção de sêmen e o crescimento folicular e ovulação na fêmea sofrem ação hormonal semelhante.

Bacon et al. (1994) e Siopes (1983) não encontraram diferenças entre o volume de sêmen de perus adultos submetidos à luz intermitente ou contínua. Resultado semelhante foi observado neste experimento.

Tabela 1 - Consumo de ração (CR), peso corporal (PC), produção de sêmen (PS), concentração do sêmen (CS), Número de células totais do sêmen (NCT), Motilidade (MOT) e vigor (VIG) dos espermatozóides de galos leves de acordo com o fotoperíodo*.

\begin{tabular}{lccccccc}
\hline \multicolumn{1}{c}{ Fotoperíodo } & $\begin{array}{c}\mathrm{CR} \\
(\mathrm{g} / \mathrm{ave} / \mathrm{dia})\end{array}$ & $\begin{array}{c}\mathrm{PC} \\
(\mathrm{g})\end{array}$ & $\begin{array}{c}\mathrm{PS} \\
(\mathrm{ml})\end{array}$ & $\begin{array}{c}\mathrm{CS} \\
\left(\mathrm{x} 10^{9}\right)\end{array}$ & $\begin{array}{c}\text { NCT } \\
\left(\mathrm{x} 10^{9}\right)\end{array}$ & $\begin{array}{c}\text { MOT } \\
(\%)\end{array}$ & $\begin{array}{c}\text { VIG } \\
(0 \text { a 5 })\end{array}$ \\
\hline Contínuo & $102,4 \mathrm{~A}$ & 1869,5 & 0,22 & 6,78 & 1,58 & 85,62 & 3,75 \\
Intermitente & $98,9 \mathrm{~B}$ & 1864,0 & 0,21 & 7,53 & 1,68 & 85,78 & 3,63 \\
Natural & $98,0 \mathrm{~B}$ & 1864,9 & 0,19 & 6,17 & 1,28 & 86,44 & 3,91 \\
\hline
\end{tabular}

"Médias seguidas de letras maiúsculas na coluna diferem significativamente pelo teste $\mathrm{Scott}-\mathrm{Knott}(\mathrm{P}<0,05)$. 
Em revisão sobre fotoperiodismo e reprodução das aves domésticas, Sauveur (1996) concluiu que o fracionamento da duração do dia com a manutenção de uma noite principal permite manter a produtividade. Esta observação também foi verificada neste experimento, ao comparar-se a produção de sêmen nos programas contínuo e intermitente.

O volume de sêmen, observado nos animais deste trabalho, foi semelhante ao encontrado por Etches (1994), Lake \& Steward (1978) e Rouvier et al. (1984) os quais relatam uma variação entre 0,05 e $0,30 \mathrm{ml}$ para galos de linhagem leve.

Não houve influência significativa $(\mathrm{P}>0,05)$ dos fotoperíodos sobre a concentração do sêmen e o número de células totais (NCT).

Não houve diferença na concentração do sêmen dos galos criados sob fotoperíodo natural ou contínuo. Concordando com este resultado, Bajpai (1962), estudando o efeito destes dois tipos de fotoperíodos sobre as características seminais de galos adultos Rhodes Island Red, também não observou diferenças na concentração do sêmen. No referido experimento, os animais que receberam 16 horas de luz contínua apresentaram maior NCT que aqueles mantidos sob luz natural, sendo este resultado provocado pelo aumento no volume de sêmen.

Com relação aos fotoperíodos contínuo e intermitente, não houve diferenças na concentração do sêmen e no NCT. Siopes (1983) também não observou diferenças nestas variáveis, em perus mantidos sob luz intermitente e aqueles que receberam luz contínua.

As concentrações do sêmen observadas neste trabalho estão de acordo com Etches (1994), Lake \& Steward (1978) e Rouvier et al. (1984) os quais relataram uma variação entre 5,0 e 7,5 x $10^{9}$ células/ml de sêmen em galos de linhagem leve.

Os resultados de motilidade (\%) e vigor dos espermatozóides ( 0 a 5) demonstram que as médias destas variáveis foram semelhantes $(\mathrm{P}>0,05)$ entre os fotoperíodos.

Bajpai (1962) não observou diferença na motilidade dos espermatozóides de galos que receberam luz natural ou contínua. Resultado semelhante foi observado na presente pesquisa.
As médias de motilidade dos espermatozóides observadas neste experimento foram bem superiores àquelas encontradas Lake (1971), citado por Garner (2004), o qual afirma que a variação média normal na taxa de motilidade espermática em galos se encontra entre $60 \%$ e $80 \%$.

Os dados de morfologia dos espermatozóides, incluindo alterações de cabeça, cauda e alterações totais dos espermatozóides (\%), estão apresentados na Tabela 2.

Os fotoperíodos não influenciaram significativamente ( $\mathrm{P}>0,05)$ dos parâmetros morfológicos avaliados.

Bajpai (1962) observou que galos adultos mantidos sob fotoperíodo contínuo apresentaram sêmen com menor percentagem de espermatozóides anormais, quando comparados com aqueles sob fotoperíodo natural. Porém, esta diferença não foi observada no presente experimento.

Também diferentemente do que foi observado neste trabalho, Siopes (1983) verificou uma menor incidência de espermatozóides morfologicamente anormais em perus submetidos à luz intermitente em comparação àqueles submetidos à luz contínua.

Lake (1971), citado por Garner (2004), afirma que a percentagem máxima de alterações totais do sêmen observadas em galos é de $15 \%$. Em perus, até $20 \%$ de alterações totais são aceitáveis para uma boa fertilidade. Pode-se, então, inferir pela observação das médias de alterações observadas neste experimento, que nenhum dos fotoperíodos utilizados exerceu efeito efetivamente prejudicial sobre a morfologia espermática.

\section{CONCLUSÃO}

Machos de linhagem leve, na idade de 24 a 39 semanas, podem ser mantidos sob fotoperíodo contínuo, intermitente ou natural crescente, sem prejuízo dos parâmetros reprodutivos.

\section{REFERÊNCIAS BIBLIOGRÁFICAS}

BACON, W. L. et al. Coordinate pattern of secretion of luteinizing hormone and testosterone in mature male turkeys under continuous and intermittent photoschedules. Poultry Science, Champaign, v. 73, p. 864-870, 1994.

Tabela 2 - Alterações de cabeça (ACAB), alterações de cauda (ACAU) e alterações totais (ATOT) dos espermatozóides de galos leves de acordo com o fotoperíodo.

\begin{tabular}{lccc}
\hline \multicolumn{1}{c}{ Fotoperíodo } & ACAB $(\%)$ & ACAU $(\%)$ & ATOT (\%) \\
\hline Contínuo & 2,29 & 5,69 & 8,18 \\
Intermitente & 2,44 & 7,16 & 9,91 \\
Natural & 2,53 & 8,75 & 11,9 \\
\hline
\end{tabular}

Ciênc. agrotec., Lavras, v. 32, n. 4, p. 1287-1291, jul./ago., 2008 
BAJPAI, P. K. The effect of photoperiodicity on semen characteristics of poultry. Poultry Science, Champaign, v. 3, p. 462-465, 1962.

BURROWS, W. H.; QUINN, J. P. The collection of spermatozoa from the domestic fowl and turkey. Poultry Science, Champaign, v. 16, p. 19-24, 1937.

CHARLES, D. R.; TUCKER, S. A. Response of modern hybrid laying strocks to change in photoperiod. British Poultry Science, London, v. 34, p. 241-254, 1993.

COTTA, J. T. B. Galinha: produção de ovos. Viçosa: Aprenda Fácil, 2002. 270 p.

ETCHES, R. J. Inseminação artificial. In: Fisiologia da reprodução de aves. Santos: Apinco, 1994. p. 117-128.

FERREIRA, D. F. SISVAR Sistema de análise estatística para dados balanceados. Lavras: UFLA/DEX, 2000. Software.

FREITAS, H. J.; COTTA, J. T. B.; OLIVEIRA, A. I. G.; GEWHER, C. E. Avaliação de programas de iluminação sobre o desempenho zootécnico de poedeiras leves. Ciência e Agrotecnologia, Lavras, v. 29, n. 2, p. 424-428, 2005.

GARNER, D. L. Espermatozóide e plasma seminal. In: HAFEZ, E. S. E.; HAFEZ, B. Reprodução animal. São Paulo: Manole, 2004. p. 97-110.
LAKE, P. E.; STEWART, J. M. Comparative physiology of turkey and fowl semen. In: CUNNINGHAM, F. J.; LAKE, P. E.; HEWITT, D. Reproductive biology of poultry. London: British Poultry Science, 1978. p. 151-160.

LEWIS, P. D.; PERRY, G. C. Response of laying hens to assimetrical interrupted lighting regimens: physiological aspects. British Poultry Science, London, v. 31, p. 45-52, 1990.

MORRIS, T. R.; BUTLER, E. A. New intermittent light programme (the reading system) for laying pullets. British Poultry Science, London, v. 36, p. 531-535, 1995.

ROUVIER, R.; TAI, J. J. L.; TAI, C. L'insemination artificielle des canes communes pour la production de mulards a Taiwan: la situation actuelle. In: Insemination artifcielle et amelioration genetique: bilan et perspectives critiques. Versailles: Institut National de la Recherche Agronomique, 1984. p. 359-368. (Les colloques de INRA, 29).

SAUVEUR, B. Photopériodisme et reproduction des oiseaux domestiques femelles. INRA Production Animal, Paris, v. 9, n. 1, p. 25-34, 1996.

SAUVEUR, B. Functionnement testiculaire. In:

Reproduction des volailles et production d'oeufs. Paris: INRA Production Animal, 1998. p. 200-208.

SIOPES, T. D. Effect of intermittent lighting on energy savings and semen characteristics of breeder tom turkeys. Poultry Science, Champaign, v. 62, p. 2265-2270, 1983. 